\title{
A CONTRIBUIÇÃO DA ECOLOGIA POLÍTICA E DO SUSTAINABLE LIVELIHOODS APPROACH NOS ESTUDOS AMBIENTAIS NO MEIO RURAL DO BRASIL: UM OLHAR SOBRE OS REASSENTADOS DE PETROLÂNDIA
}

\author{
Guilherme José Ferreira Araújo* \\ Universidade Federal de Pernambuco** \\ Edvânia Tôrres Aguiar Gomes*** \\ Universidade Federal de Pernambuco****
}

Resumo: A ecologia política e o sustainable livelihood approach são respectivamente abordagens teórica e metodológica voltadas para o debate sobre temas relacionados à desigualdade social e ao estabelecimento de metas para o combate à pobreza. Ambas são recentes no campo da pesquisa científica. A ecologia política foi germinada no período das grandes conferências ambientais da ONU, e o sustainable livelihood approach foi concebido durante a década de 1980 com vistas a entender os principais fatores que contribuem com a pobreza em áreas rurais de países africanos. Este artigo tem o objetivo de desenvolver uma aproximação teórica entre as abordagens estudadas e dessa forma contribuir com as discussões sobre as desigualdades no acesso aos recursos naturais e os desdobramentos para a pequena produção agrícola no Brasil. Para o estabelecimento deste trabalho foi realizado um amplo levantamento bibliográfico para identificar os pontos que unem a teoria da ecologia política e a prática metodológica do sustainable livelihood approach. Em seguida foram elencados os principais problemas identificados nas pesquisas de campo em Petrolândia e estabelecidas relações com as abordagens em questão. Nesse quesito, foram analisados pequenos produtores de coco dos perímetros irrigados de Apolônio Sales e Icó-Mandantes. Nesses perímetros encontram-se agricultores com diferentes contextos socioeconômicos, porém com a mesma origem de reassentamento e subsídio estatal. Todos são oriundos de uma transferência forçada em função da construção da Usina Hidrelétrica Luiz Gonzaga. Nesse sentido, o estudo pretende iniciar um debate sobre as principais razões dessas diferenças e visualizar prováveis soluções.

Palavras-chave: Conflitos ambientais. Perímetros irrigados. Semiárido. Coco.

\section{THE CONTRIBUITION OF THE POLITICAL ECOLOGY AND THE SUSTAINABLE LIVELIHOOD APPROACH IN THE ENVIRONMENTAL STUDIES IN THE BRAZIL RURAL AREA: THE CASE OF RESETTLED PEOPLE FROM PETROLÂNDIA}

Abstract: The political ecology and the sustainable livelihood approach are theoretical and methodological tools of analyses, which aims to debate about theme concerning the social inequality and the establishment of goals to coping against poverty. Both are recent in the field of the scientific research. The political ecology was born at the period of UN environmental conferences and the sustainable livelihood approach was conceived during the 80 's aiming to understand the major factors, which contribute with the poverty in rural area in some Africans country. This article aims to approach both field in order to discuss about the inequality on the natural resource access and the repercussion on the agricultural production in Brazil. This work was done with literature review in order to identify how both approach can be used complementarily. Afterwards were selected the major problems identified during the field works in Petrolândia Municipality and linked with both theme. Several interviews were done with small-scale coconut farmers from the resettlement of Apolônio Sales and Icó-Mandantes. In these both resettlements there are farmers with different socio-economic context, however most of them are from the same origin. They are resettled people of a forced migration in order to construction of Luiz Gonzaga Hydroelectric Power. So, this study has also the purpose to begin a debate about the reason of the farmers socio-economic difference and to view possible solutions.

Keywords: Environmental conflicts. Irrigated schemes. Semiarid. Coconut.

\footnotetext{
* Doutor em Geografia (UFPE). Professor substituto do Colégio de Aplicação (UFPE). E-mail: guigeorecife@gmail.com

** Departamento de Ciências Geográficas (DCG-UFPE), Centro de Filosofia e Ciências Humanas (CFCH), $6^{\circ}$ andar. Avenida Acadêmico Hélio Ramos, s/n - Cidade Universitária, CEP: 50.740-530, Caixa Postal 7803 - Recife-PE.

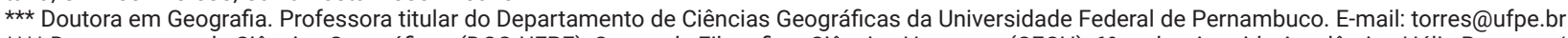

$\star \star \star \star$ Departamento de Ciências Geográficas (DCG-UFPE), Centro de Filosofia e Ciências Humanas (CFCH), $6^{\circ}$ andar. Avenida Acadêmico Hélio Ramos, s/n - Cidade Universitária, CEP: 50.740-530, Caixa Postal 7803 - Recife-PE.
} 
Resumen: La ecología política y el sustainable livelihood approach son respectivamente, enfoques teóricos y metodológicos dirigidos al debate sobre temas relacionados con la desigualdad social y el establecimiento de metas para la lucha contra la pobreza. Ambos son recientes en el campo de la investigación científica. La ecología política fue germinada en el período de las grandes conferencias ambientales de la ONU y el sustainable livelihood approach fue concebido durante la década de 1980 para comprender los principales factores promotores de pobreza en las zonas rurales de los países africanos. Este artículo tiene el objetivo de desarrollar una aproximación teórica entre los enfoques estudiados y de esa forma contribuir con las discusiones sobre las desigualdades en el acceso a los recursos naturales y los desdoblamientos para la pequeña producción agrícola en Brasil. Para la construcción de este trabajo se llevó a cabo un amplio levantamiento bibliográfico com el fin de identificar los puntos que unen la teoría de la ecología política y la práctica metodológica del sustainable livelihood approach. También se codificaron los principales problemas identificados en las encuestas aplicadas en Petrolândia y se establecieron relaciones con los enfoques en cuestión. En este aspecto se analizaron pequeños productores de coco de los Perímetros Irrigados de Apolônio Sales e Icó-Mandantes. En esos perímetros se encuentran agricultores con diferentes contextos socioeconómicos, pero con el mismo origen de reasentamiento y subsidio estatal. Todos proceden de una transferencia forzada en función de la construcción de la Planta Hidroeléctrica Luiz Gonzaga. En este sentido, el estudio pretende iniciar un debate sobre las principales razones de estas diferencias y visualizar probables soluciones.

Palabras clave: Conflictos ambientales. Perímetros irrigados. Semiárido. Coco.

\section{Introdução}

A ecologia política e o sustainable livelihood approach são abordagens recentemente implantadas no campo da pesquisa científica. No final da década de 1970 iniciaram-se as discussões acerca de problemas ambientais sob a luz da ecologia política e o sustainable livelihood approach foi lançado entre o final da década de 1980 e começo da década de 1990, para servir como uma ferramenta de análise nos estudos das estratégias de subsistência de pequenos produtores.

Ambas as abordagens estavam voltadas a contribuir com estudos contra a desigualdade social e estabelecimento de metas para o combate à pobreza. A ecologia política corresponde a um conceito e uma perspectiva de análise dos problemas ambientais por um viés político e ideológico, com o objetivo de compreender e contribuir com a redução dos conflitos ambientais nos países subdesenvolvidos. Normalmente, a questão da pobreza nos países pobres está relacionada às adversas condições de subsistência. Nesse sentido, a perspectiva da ecologia política proporciona o estabelecimento de uma ponte para uma análise mais profunda sobre os aspectos referentes às relações entre sociedade $\mathrm{e}$ natureza.

O sustainable livelihood approach foi criado por Chambers e Conway ${ }^{1}$ na Inglaterra. É considerado um instrumento metodológico para análises em pesquisas sociais, que se utiliza de um framework ${ }^{2}$ contendo um cenário real de vulnerabilidade dos pequenos produtores, com cinco ativos de análise das condições da sua subsistência, mais o âmbito político, as estratégias aplicadas para superar o cenário de vulnerabilidade e os resultados dessas estratégias. A partir dessa análise

\footnotetext{
VVer Chambers e Conway (1991).
}

${ }^{2} \mathrm{Na}$ seção referente à abordagem do sustainable livelihoods approach o termo framework é discutido mais amplamente. deve-se aprofundar a compreensão do pesquisador acerca da subsistência e da sustentabilidade de um determinado indivíduo e servir de suporte para elaboração de políticas públicas em prol da equidade social e da justiça ambiental.

O objetivo deste artigo é desenvolver uma aproximação teórica entre a ecologia política e o sustainable livelihoods approach com vistas de contribuir com as discussões sobre as desigualdades no acesso aos recursos naturais e os desdobramentos para a pequena produção agrícola. 0 âmago desta análise visa responder se existe possibilidade de desenvolver uma análise científica utilizando a ecologia política como uma abordagem norteadora em estudos ambientais e o sustainable livelihoods approach como ferramenta para aplicar em um determinado caso. E se ambas as formas de análises podem ser utilizadas para estudos no meio rural brasileiro, tendo em vista o ambiente e o período histórico nos quais foi concebido.

A ênfase deste artigo será estabelecer relações entre as abordagens citadas anteriormente, no entanto serão utilizados como exemplos empíricos estudos com os reassentados do Município de Petrolândia, Pernambuco. Para este tópico foram pesquisados pequenos produtores de coco dos perímetros irrigados de Apolônio Sales e Icó-Mandantes, os quais são oriundos de um contexto de migração involuntária em função da construção da Usina Hidrelétrica Luiz Gonzaga.

0 ensaio é parte de um estudo de doutorado que integra o Projeto INNOVATE ${ }^{3}$ - Interplay among multiple

\footnotetext{
${ }^{3}$ O Projeto INNOVATE é uma parceria desenvolvida entre institutos de pesquisa brasileiros e alemães. Liderado pela Universidade Federal de Pernambuco e a Universidade Técnica de Berlim, as instituições tem o objetivo de estudar os usos e a ocupação do solo na região de Itaparica no semiárido pernambucano e baiano. O projeto é composto por sete subprojetos com cientistas de diversas áreas. Possui financiamento do CNPq e da Capes e também corresponde a um dos doze projetos científicos na área de gestão sustentável da terra financiados pelo Ministério de Pesquisa e Educação da Alemanha.
} 
uses of water reservoirs via innovative coupling of substance cycles in aquatic and terrestrial ecosystems -, parceria binacional entre universidades do Brasil e da Alemanha.

O trabalho se inicia discorrendo sobre a ecologia política, buscando enquadrar cientificamente o termo, como também relacionar seu campo de pesquisa e origens na geografia. Em seguida o debate se propõe a desenvolver uma compreensão teórica sobre o sustainable livelihoods approach, descrevendo os elementos apontados no seu framework e sua relação com os estudos ambientais. Por fim, o artigo apresenta as questões ambientais em Petrolândia a partir da perspectiva das abordagens trabalhadas.

\section{Pressupostos epistemológicos da ecologia política}

De acordo com Bryant e Bailey (2000) os primórdios da ecologia política estão nos anos 1970, e durante os anos 1980 e 1990 ocorreu sua expansão. Nesse período o conceito criou bases para nos dias atuais se consolidar como uma fonte rica para pesquisas inovadoras que abordam as questões ambientais nos países do eixo sul.

A ecologia política vem se configurando como área provocadora no âmbito de pesquisas interdisciplinares. Segundo os pesquisadores deste campo, as suas origens partem da interface entre as ciências naturais, sociais e política. Durante a década de 1980 foi amplamente definida, sofrendo maior influência de pesquisadores dos Estados Unidos e do Reino Unido (KRINGS, 2013).

Segundo Robbins (2005), este campo traz uma abordagem política para discutir os problemas ambientais. Dessa forma, a questão ambiental, especificamente os acessos aos recursos naturais, exploração/extração de matéria-prima e degradação do ambiente são pontos analisados politicamente.

Diante dos avanços dos debates sobre as questões ambientais, principalmente na década de 1980, a ecologia política ganhou maior visibilidade, representando uma reflexão que surge em função da emergente necessidade por uma abordagem analítica que integrasse a compreensão política e o ambiente natural no contexto da intensificação das degradações e demais problemas identificados nos países do antigo Terceiro Mundo (BRYANT; BAILEY, 2000).

De acordo com Zhouri (2006), a ecologia política surge em um momento em que se buscavam novas bases para as Ciências Sociais. Nessa ocasião, a proposta era de superar dicotomias como objetividade-subjetividade, indivíduo-sociedade, natureza-cultura. Toda a crítica era oriunda de movimentos políticos e acadêmicos que estavam voltados primordialmente para o surgimento da sociedade industrial.

\section{As raízes da ecologia política}

Antes de continuar o debate neste campo de estudo, é preciso estabelecer as origens que influenciaram o pensamento atual. De acordo com Robbins (2005), o aristocrata russo Peter Alexeivich Kropotkin foi o primeiro membro da linhagem da ecologia política. No ano de 1921, quando faleceu, o geógrafo russo já era mundialmente conhecido como um filósofo anarquista, cujos trabalhos acadêmicos enfatizavam as relações entre a sociedade e a natureza.

Os estudos de Kropotkin no oeste russo, nas proximidades da Manchúria, e sua experiência com os Tungus, agricultores, entre outros nativos, foram pioneiros na Rússia do século XIX e começo do século $X X$, visto que diante das adversidades da região não existia nenhuma perspectiva de se explorar essa porção do país. Seu esforço originou mais pesquisas e debates sobre formas de crescimento de sociedades. E as evidências colecionadas nas expedições junto a pessoas e animais convenceu o cientista de que a sobrevivência e a evolução são resultados de uma ajuda mútua, organização e cooperação entre indivíduos (ROBBINS, 2005).

A escocesa Mary Fairfax Sommerville desenvolveu nos finais do século XVIII e início do século XIX críticas voltadas contra a escravidão, a apropriação de terras das populações aborígines, as imprudentes formas de degradação ambiental pela exploração humana através dos usos excessivos, das extrações e da introdução de espécies exóticas, em detrimento das espécies nativas. Seguindo um caminho próprio, suas pesquisas tinham um viés que apontava para os impactos humanos sobre a terra e os impactos que a terra proporcionava às sociedades. Com inúmeros artigos científicos publicados, Sommerville teve acesso a espaços geralmente restritos a homens no campo da ciência, e, mesmo diante dos preconceitos por causa do seu gênero, ela conseguiu notoriedade com seus trabalhos, tornando-se um dos braços importantes para os estudos atuais da ecologia política (ROBBINS, 2005).

O pai da geografia moderna, Alexander Von Humboldt, também é considerado um dos primeiros a fazer ecologia política em sua prática científica. Seus estudos durantes as expedições ao redor mundo durante o século XIX proporcionaram ao prussiano entrar em contato com as mais variadas formas de vida humana e não humana em meio a difíceis condições políticas e econômicas. Essas condições permitiram com que Humboldt desenvolvesse 
uma aparente apreciação pelo contexto político e econômico que as pessoas enfrentavam no seu dia a dia (ROBBINS, 2005).

O francês Elisee Reclus teve uma trajetória fundamental na geografia. Sua obra A Terra: uma história descritiva foi considerada apenas um pouco menos ambiciosa que Cosmos, a obra mais conhecida de Humboldt. Porém, na obra de Reclus a análise sobre política e as questões relacionadas ao tópico homem e ambiente eram mais explícitas que no trabalho do prussiano. 0 geógrafo francês contribuiu no debate sobre a questão da justiça, especialmente para os trabalhadores, apontando sua relação com as transformações sociais e ecológicas, além de desafiar a noção contemporânea de estrutura social e práticas ecológicas (ROBBINS, 2005).

O britânico Alfred Russel Wallace trouxe importantes contribuições para as raízes do pensamento da ecologia política. O geógrafo e também naturalista realizou expedições na Amazônia e no sul da América Latina. Nesse período, desenvolveu estudos sobre dominação social e imperialismo. Realizou uma crítica sobre a hierarquia social e a gestão da terra nos lugares por onde andou, ao mesmo tempo em que trocava correspondências com Charles Darwin construindo a teoria da seleção natural. Wallace relacionou evolução, justiça social e gestão da terra para oferecer uma crítica ao racismo e o já emergente darwinismo social (ROBBINS, 2005).

Outro geógrafo de influência para os estudos da ecologia política foi o germânico Friedrich Ratzel. Suas pesquisas foram amplamente defendidas nos Estados Unidos pelos cientistas William Morris Davis, Ellsworth Huntington e Ellen Churchill Semple, as quais abordavam que as influencias das condições ambientais determinavam a capacidade e as condições culturais dos povos. Seus seguidores buscavam assiduamente codificar essa perspectiva dentro da prática científica. Posteriormente esse pensamento foi criticado como racista (ROBBINS, 2005).

\section{As raízes da ecologia política no Brasil}

0 médico-geógrafo Josué de Castro foi um dos pioneiros no Brasil em pesquisas no que hoje se intitula ecologia política. Natural de Recife, local onde germinou seus estudos neste campo, Josué publicou em 1946 a obra Geografia da fome. A preocupação do autor era com a desigual distribuição dos alimentos, que influenciava a nutrição da população. Seu trabalho aponta lugares de subnutrição endêmica e sua relação com a falta de um plano de produção agrícola adequado (ANDRADE, 1997).

No seu ensaio Alimentação e raça, publicado em 1936, o autor apontou que causas da pobreza e da subnutrição tinham raízes sociais e não eram determinadas pelos fatores ambientais, como era abordado pelo pensamento dominante da época (ANDRADE, 1997).

O geógrafo Hilgard O’Reilly Sternberg, filho de um alemão e uma irlandesa, iniciou sua inclinação para os estudos ambientais por ocasião do seu doutoramento, concluído em 1956. Sua tese, intitulada A água e o homem na várzea do Careiro, tratou sobre as questões envolvendo a população ribeirinha e os cursos d'água. Nesse trabalho ele analisou as graves consequências do desmatamento para as comunidades, como as enchentes que ceifaram a vida de muitos dos habitantes (GUIMARÃES, 2011).

Antes de falecer em 2011, ocupava a cadeira de professor emérito de geografia na Universidade da Califórnia, em Berkeley. Suas análises enfatizavam a relação entre sociedade e natureza. O campo de pesquisa utilizado era a floresta amazônica brasileira. 0 foco do seu trabalho era questionar como comunidades humanas afetam o meio ambiente, por meio do uso impróprio do solo, da água, da flora, da fauna e através da concentração dos recursos nas mãos de poucos (SANDERS, 2011).

O geógrafo e ambientalista Aziz Nacib Ab'Saber teve um papel fundamental na luta pela questão ambiental no Brasil, destacando-se seus esforços pela preservação da Amazônia e da Caatinga. O cientista defendeu seu doutorado em 1956 com a tese Geomorfologia do sítio urbano de São Paulo. Alguns de seus trabalhos foram premiados, como o livro Amazônia: do discurso à praxis. Os estudos do pesquisador também estavam voltados para os problemas urbanísticos e ambientais de grandes cidades. Ab'Saber sempre esteve à frente de embates de cunho ambiental, e os últimos estavam relacionados à questão do Código Florestal Brasileiro e à transposição do Rio São Francisco (DOURADO, 2012).

0 pensamento da ecologia política também estava representado na obra de Manuel Correia de Andrade, um pernambucano que se dedicou ao estudo do espaço agrário brasileiro, sobretudo do Nordeste do Brasil. Em A terra e o homem no Nordeste, publicada em 1963, o professor Manuel debateu as relações injustas de posse da terra e a proletarização do trabalhador rural (ANDRADE, 2011). Andrade também apontou problemas no cerne da sociedade originado pela desigual forma de distribuição de terras, que se originou desde o período colonial com a escravidão até os dias atuais com a ausência de uma reforma agrária (MAIA, 2009).

Definição da abordagem da ecologia política

Quando a ecologia política surge propriamente dita 
como campo de pesquisa, ela passa a ser definida com o objetivo de aprofundar compreensão sobre a complexa relação entre a natureza e a sociedade por meio de uma análise criteriosa. 0 foco prioriza as formas de acesso e controle dos recursos naturais, com ênfase nas implicações que essa estrutura pode provocar para o meio ambiente e a subsistência dos pequenos produtores rurais (ROBBINS apud WATTS, 2000).

São dedicados esforços no sentido de entender que as mudanças ambientais e as condições ecológicas também são resultado de processos políticos, em que os custos e benefícios oriundos dessas mudanças são distribuídos desigualmente entre os agentes (BRYANT; BAILEY, 2000).

O objetivo é desenvolver uma reflexão crítica para expor o que está errado na gestão e na mudança ambiental, enquanto por outro lado são aplicados esforços para pensar criteriosamente em alternativas ou adaptações frente ao problema da ineficiente gestão e exploração dos recursos naturais (ROBBINS, 2005).

De acordo com Robbins (2005), a ecologia política possui quatro teses nas quais desenvolve seu campo de análise. A primeira tese aborda a questão da degradação e da marginalização, onde são debatidas as razões das mudanças ambientais e como estas vieram a ocorrer. Aqui o estudo é orientado sob a perspectiva de que a degradação da terra é oriunda principalmente do contexto político e econômico, contrariando afirmações que apontam para os marginalizados como os principais originadores das alterações no ambiente.

A segunda tese trata dos conflitos ambientais. São levantadas questões concernentes ao acesso ao ambiente. A preocupação aqui é com quem tem acesso e por quê. Os conflitos nesta análise são apresentados para contribuir no debate das lutas de gênero, de classes e raciais. A tese busca analisar, por exemplo, a crescente escassez de produtos oriundos de terras apropriadas por autoridades do Estado, empresas privadas ou das elites sociais, que são os principais responsáveis em iniciar e acelerar o conflito entre os grupos (ROBBINS, 2005).

Nessa perspectiva, os conflitos ambientais se enraízam na sociedade quando determinado grupo (gênero, classe ou etnia) passa a ter o controle sobre os recursos coletivos em detrimento dos outros. Normalmente esse processo ocorre com apoio de políticas públicas intervencionistas desenvolvidas pelas autoridades estatais ou em conjunto com agentes privados (ROBBINS, 2005). Esses conflitos também podem ser originados a longo prazo em função de medidas estabelecidas, cujos resultados danosos necessitam de um tempo maior para serem percebidos.

A terceira tese apontada é referente à conservação e controle. Aqui são trabalhadas as falhas nesse processo, como também a exclusão política e econômica. A compreensão desenvolvida nesta abordagem discute que os esforços para conservação ambiental, geralmente compreendidos como uma atitude benigna, também podem ter efeitos perversos para as comunidades. Por exemplo, quando são estabelecidas áreas de preservação que expropriam antigos habitantes daquela área. Nesse caso, forma-se um cenário de exclusão diante de uma proposta de preservação ambiental (ROBBINS, 2005).

A quarta tese se debruça sobre a questão da identidade ambiental e os movimentos sociais. Neste ponto os estudos se dirigem para os levantes sociais, enfatizando os principais agentes, o ambiente e como essas ações são desenvolvidas. As forças políticas e sociais são apresentadas para relacionar as questões básicas da subsistência e a proteção ambiental (ROBBINS, 2005).

Diante da complexidade de sua abordagem, a ecologia política estabelece vínculos com diversos campos disciplinares, e portanto tem uma origem intertransdisciplinar. São identificadas raízes nas áreas da antropologia, da sociologia, da história, das ciências políticas e de áreas tecnológicas (ZIMMERER; BASSET, 2003).

O termo ecologia política, por si só, não traz uma ideia específica em sua análise. Por se tratar de um conceito genérico, enuncia uma ampla definição. Atualmente, identificam-se diferentes formas de aprofundar sua aplicação. Alguns autores se debruçam no âmbito da economia política, outros pontuam aspectos formais de instituições políticas, enquanto outro grupo se define mais focado nas questões voltadas para as mudanças ambientais (ROBBINS, 2005).

Os campos interdisciplinares, como os estudos ambientais e tecnológicos, são de grande importância para a abordagem em ecologia política. Com o enfoque geográfico é necessário, ao mesmo tempo, entender as contribuições que este campo proporciona para uma profunda compreensão das mudanças ambientais, em que a ênfase são as interações entre sociedade e natureza utilizando a ecologia política como escala (ZIMMERER; BASSET, 2003).

De acordo com Coy (2013), a ecologia política utiliza as relações entre sociedade e natureza como sua principal categoria. Seu campo de pesquisa busca uma abordagem com fins de analisar as relações conflituosas entre a sociedade e a natureza / homem e meio ambiente, como, também, as estratégias de sobrevivências dos grupos mais vulneráveis. Por exemplo, os projetos para instalação de infraestrutura de grande porte na Amazônia e suas consequências para os grupos indígenas locais, como a desterritorialização desses grupos e os demais impactos provocados nas comunidades locais que também são relocadas ou têm sua dinâmica econômica alterada.

A questão crucial que se busca entender são as relações entre as transformações sociais e as condições 
da natureza que estão intrinsecamente relacionadas com as tendências econômicas controladas por agentes globais. 0 que será representado e concretizado através do acesso e do uso dos recursos naturais tanto para fins econômicos diretamente público ou privado (COY, 2013).

A análise das relações sociais frente ao uso do ambiente evoca, por si só, uma discussão politizada, ou seja, uma visão política das relações entre sociedade e natureza, que é o principal tópico de pesquisa da ecologia política. Associado a este âmbito surgem questionamentos acerca dos diferentes cenários de vulnerabilidade e quais os agentes que ocupam posição central. A pergunta que se pretende responder é quem ganha e quem perde nesse jogo de relações? Como são divididos os custos nesse cenário? Identificar as injustiças nesse processo faz parte de um papel fundamental neste estudo (COY, 2013).

Os trabalhos desenvolvidos no âmbito da ecologia política têm trazido uma contribuição significativa para aprofundar a compreensão das relações entre sociedade e natureza numa perspectiva geográfica. A abordagem abrange os esforços aplicados para engajar a dimensão política e ecológica diante das questões ambientais de um modo integrado (ZIMMERER; BASSET, 2003).

A geografia se diferencia das outras disciplinas em função da sua análise dos atuais processos de globalização ambiental. Nessa perspectiva, a compreensão deste campo vem fortalecer o entendimento sobre as esparsas e distintas decisões e atividades em escala global referente ao ambiente local, especialmente concernente aos recursos naturais, como também acerca das mudanças econômicas, políticas e culturais. Nesse sentido, é fundamental compreender quais são os instrumentos motrizes que originam essas transformações (ZIMMERER; BASSET, 2003).

A ecologia política no âmbito geográfico analisa os sistemas de recursos como ecossistemas utilizados sob a perspectiva política, que são pela natureza e pela constante transformação interligados com as atividades humanas e tipicamente diferenciados pelas relações de poder associadas com as questões de gênero, de étnica, de classe ou de renda (ZIMMERER; BASSET, 2003).

Mesmo diante de diversas abordagens no campo de pesquisa em ecologia política, seus especialistas estão em comum acordo em pontos básicos. Destacase a concordância de que os problemas ambientais enfrentados pelos países subdesenvolvidos e os de economia emergentes não são apenas um reflexo de políticas públicas ineficientes ou de falhas no mercado. Essas forças foram cooptadas durante a ampla difusão do capitalismo, principalmente a partir do século XIX (BRYANT; BAILEY, 2000).

Dessa forma, as pesquisas em ecologia política têm sido desenvolvidas principalmente para descrever os impactos no tempo e no espaço que a força do capitalismo provocou no ambiente natural e social dos países do sul. Diferentemente dos países centrais, a pobreza e os conflitos ambientais nos países subdesenvolvidos são predominantemente baseados na subsistência. Nesse sentido, esse ramo da pesquisa social tem a chave para estabelecer as relações existentes entre pobreza e riqueza, degradação ambiental e processo político (BRYANT; BAILEY, 2000).

Os desafios desse campo são entender e alertar a sociedade para a ausência ou a quebra de compatibilidade das ações de agentes do espaço, as quais resultam em desigualdades no acesso aos recursos naturais. Nesse caso, são elencados dois grupos distintos, um representado por agentes dominadores, que são aqueles que possuem maior privilégio na aquisição dos recursos do território. 0 outro grupo é representado pelos agentes desprovidos de igual oportunidade de acessar os recursos naturais (ASCELRALD, 2010).

A principal contribuição da ecologia política é para fortalecer o debate acerca dos problemas referentes às relações sociedade e natureza com foco em conflitos e mudanças ambientais nos países do eixo sul. As questões como degradação ambiental (solo, água e ar), perda da biodiversidade, mudança climática global fazem parte da pauta de análise, assim como seus processos, extensão e as principais causas que a originaram (KRINGS, 2011).

0 enfoque inicial da abordagem em ecologia política foi sobre o espaço rural, enfatizando as questões que envolvem a sociedade e os recursos naturais, especialmente o solo e a agricultura dos países em desenvolvimento do eixo sul do globo. Foram incluídas nesse aspecto abordagens crescentemente geográficas em consideração aos cenários urbano-industrial dos países do eixo norte do globo (ZIMMERER; BASSET, 2003).

Para a ecologia política é importante compreender que as mudanças ambientais trazem repercussões conflituosas nas decisões políticas ${ }^{4}$, e estas passam também a influenciar a sociedade, as relações comerciais, os interesses dos indivíduos, seja em escala local, nacional ou global. Neste caso, a dimensão histórica tem papel fundamental para compreender como os processos se originaram (KRINGS, 2011).

De acordo com Zimmerer e Basset (2003), a degradação ambiental alcança os espaços do campo com maior intensidade quando as forças econômicas entram em comunidades rurais fazendo com que as instituições locais percam sua flexibilidade.

De acordo com Gudynas (2010), os países subdesenvolvidos sempre tiveram o papel de servir como espaço de exploração dos recursos naturais, sem

${ }^{4}$ Robbins (2005) aponta que as mudanças ambientais também podem ser originadas devido às repercussões de decisões políticas conflituosas. 
considerar a possibilidade da escassez em função do excessivo uso. Na América Latina, até o século XIX, a degradação ambiental ocorria em função das ordens dos países europeus; nos dias atuais, a degradação ampliouse e tem a formalização via legislação local.

\section{Um olhar sobre os conflitos ambientais na América Latina}

As medidas para o crescimento econômico adotadas durante o século XIX foram amplamente fortalecidas com o objetivo de intensificar o controle sobre os recursos naturais. Dessa forma, identificam-se modos de usos da natureza que resultam em conflitos ambientais atuais, os quais foram causados pela maior integração com a economia capitalista global, pela dependência dos recursos naturais, pela degradação ambiental e pelo poder político centralizado (BRYANT; BAILEY, 2000).

Conflitos socioambientais são aqueles relacionados ao acesso e também ao controle dos recursos naturais e do território. Os agentes envolvidos enfrentam interesses e valores divergentes, diante de um contexto de grande assimetria de poder. Esses conflitos apresentam diferentes concepções sobre o território, sobre a natureza e sobre o ambiente, ao passo que vão estabelecendo uma disputa acerca do que se entende sobre desenvolvimento (SVAMPA, 2013).

A instalação de megaprojetos configura-se como o estabelecimento dos conflitos, visto que todo ele tem a tendência de reconfigurar o território em sua globalidade. Normalmente, são impostos sem a autorização das populações tradicionais, gerando assim fortes divisões na sociedade (SVAMPA, 2013).

Segundo Ascelrald (2010), os conflitos ambientais ocorrem, de fato, no momento em que a legitimidade de certas formas de domínio do espaço é contestada diante da alegação da existência da sobreposição de práticas espaciais indesejadas. A ocorrência de uma prática interage com o espaço em detrimento de outra, normalmente mais antiga.

$\mathrm{Na}$ realidade social concreta, todo ambiente se apresenta com agentes antagônicos, e estes possuem significados culturais que não compactuam, pois os modos de apropriação material e simbólica do espaço também são diferentes. Nesse sentido, a desigualdade ambiental encontra possibilidade de se instalar mais facilmente, e, quando sobreposta às questões de ordem social, os conflitos tendem cada vez mais a se multiplicar (ASCELRALD, 2010).

$\mathrm{Na}$ análise sobre os conflitos ambientais são observadas diversas formas de usos dos recursos naturais, variando entre questões do direito ao acesso pelas populações que já tinham a tradição de explorar determinado espaço, também por impactos de práticas mercantis no mesmo ambiente ou pelas diferentes ações espaciais mediadas por bens não mercantis como a água, a terra, $\mathrm{o}$ ar, a biodiversidade, entre outros, e normalmente nesses espaços há uma tendência de prevalência dos agentes mais fortes (ASCELRALD, 2010).

No Brasil existem exemplos claros de como os conflitos ambientais são estabelecidos. Os casos de localização de projetos de instalação de infraestrutura priorizam áreas ocupadas por grupos de baixa renda, e normalmente são comunidades tradicionais, indígenas, quilombolas, atingidas por barragens (ASCELRALD, 2010).

Esse tipo de exploração ou dominação do espaço natural, resultando na desestruturação das condições de produção dos pequenos produtores ou comunidades, é nomeado de acumulação por espoliação, de onde são retirados os recursos de um grupo desprivilegiado politicamente para fortalecer 0 desenvolvimento capitalista (Harvey, 2005). O Brasil tem se aprofundado nesse tipo de processo ao passo da crescente inserção de sua economia no mercado globalizado (ASCELRALD, 2010).

O período colonial nos países subdesenvolvidos deixou um legado ambientalmente degradante e de crescimento econômico dependente da exploração dos recursos naturais. Na América Latina, por exemplo, a organização político-administrativa da colônia era estabelecida com o intuito de controlar as pessoas e o espaço natural localizados em sua jurisdição (ANDRADE, 2011).

No Brasil, desde o século XVI já existe exploração de matéria-prima para a Europa. 0 primeiro exemplo foi o extrativismo do pau-brasil no Nordeste do País, em seguida houve a corrida dos minerais preciosos por todo o País, principalmente no eixo centro-sul (ANDRADE, 2011).

Nos últimos anos do século $X X$, tem se intensificado a expansão de megaprojetos que tendem a aumentar o controle sobre os recursos naturais, a extração e a exportação de matérias-primas do espaço latinoamericano, contudo, sem aumentar o seu valor agregado (SVAMPA, 2013).

No último decênio, a América Latina vivenciou plenamente a efetivação do Consenso de Washington, já iniciada na década de 1990, como também sua passagem para o Consenso das Commodities, baseada na exportação em grande escala dos bens primários. Esse segundo consenso se caracteriza pelo ingresso de uma nova ordem com um viés econômico, político e ideológico, sustentado pelo crescimento dos preços internacionais das matérias-primas e dos bens de consumo, os quais possuem uma constante demanda 
nos países centrais e emergentes. A aplicação desse modelo traz resultados antagônicos para a região. De um lado é notório o crescimento econômico e o aumento das reservas monetárias, porém do outro lado são visualizadas facilmente as assimetrias sociais, como a concentração de renda e a desigualdade nos privilégios conquistados pela exploração dos recursos (SVAMPA, 2013).

A América Latina reproduz em grande escala os padrões de desenvolvimento pautados numa perspectiva antropocêntrica e instrumental. As exportações estão em sua maioria baseadas em recursos primários. Com a exceção do Brasil, todos os países do Mercosul possuem altos níveis de exportações de matérias-primas como os minerais, petróleo, gás natural, produtos agropecuários, entre outros. Países como Chile e Bolívia tem $80 \%$ de suas exportações relacionadas a esses produtos. Para isso é necessária a apropriação de extensas áreas, e comumente a ocupação dessas terras traz resultados negativos para os seus antigos proprietários (GUDYNAS, 2010).

A partir do ponto de vista da lógica de acumulação o consenso de commodities contribui profundamente com a questão da desposse de terras, de recursos naturais e dos territórios, produzindo assim novas formas de dependência e dominação. Alguns elementos são intrínsecos a essa dinâmica, por exemplo a escala dos empreendimentos, a tendência a monocultura, a falta de diversificação econômica e uma lógica de ocupação territorial notavelmente degradante (SVAMPA, 2013).

A escala dos empreendimentos determina a sua área de atuação, como também sua força no território. Em função de sua concentração econômica e os objetivos político-econômicos, tais empreendimentos tendem a se consolidar no seu território de atuação com uma lógica neocolonial, provocando uma fragmentação social e regional, fortalecendo a criação de espaços produtivos dependentes do mercado internacional. Alguns exemplos claros são as indústrias de mineração a céu aberto, a exploração de petróleo e gás, a construção de hidrelétricas, a expansão pesqueira e florestal (SVAMPA, 2013).

Diante das condições naturais que a América Latina possui, a região poderia se converter em um espaço para obter um intercâmbio regional e estabelecer um menor uso de commodities e reformar seu espaço institucional para as questões ambientais. Tendo em vista a atual estrutura dos seus países, estes não tratam dos temas ambientais adequadamente (GUDYNAS, 2004). Nos países latino-americanos, assim como nos demais países subdesenvolvidos, as políticas ambientais diferem dos países centrais. Nos primeiros existe uma fragilidade em relação à conservação, prevalecendo a degradação. No segundo grupo de países há uma tendência maior à conservação ambiental (BRYANT; BAILEY, 2000), uma vez que nos últimos anos os movimentos pró-preservação do patrimônio histórico-natural têm conquistado grandes espaços no debate político.

\section{0"sustainable livelihoods approach", uma ferramenta para estudos no meio rural}

O sustainable livelihoods approach ${ }^{5}$ (SLA) é uma ferramenta de análise com a proposta de aperfeiçoar a compreensão do pesquisador acerca da subsistência e da sustentabilidade de um determinado indivíduo. Normalmente, os estudos desenvolvidos com essa metodologia são aplicados para analisar a subsistência de indivíduos com baixas condições socioeconômicas (CHAMBERS; CONWAY, 1991).

O termo sustainable livelihood traduzido literalmente para o português significa subsistência sustentável ou - como amplamente aplicado por autores nativos do português - meios de vida sustentáveis. Para esta pesquisa optou-se manter o termo no original para não ser confundido com o termo meio de vida, anteriormente conhecido na sociologia rural, o qual não corresponde completamente com o SLA. O conceito de meio de vida foi pioneiramente utilizado pelo sociólogo brasileiro Antônio Candido na década de 1950, em sua obra Os parceiros do Rio Bonito: estudo sobre o caipira brasileiro e a transformação dos seus meios de vida (PERERIRA; SOUZA; SCNEIDER, 2010). Embora ambos os termos (meio de vida e sustainable livelihoods) sejam pertencentes à mesma genealogia, possuem algumas diferenças conceituais, o que impossibilita sua discussão em conjunto.

Também não será utilizado o termo "subsistência sustentável", mesmo com tradução equivalente, para não surgir uma falsa ideia sobre o que está sendo proposto para discussão. Dessa forma, o pensamento será mantido tal qual foi concebido, com vistas a evitar prováveis limitações na tradução, uma vez que este é um termo carregado de questões que envolvem uma complexidade cultural que, normalmente, não se exprimem literalmente para idiomas distintos.

O SLA foi desenvolvido no final da década de 1980 e início da década de 1990 pelo Instituto de Estudos sobre Desenvolvimento ${ }^{6}$ (IDS), entre outros grupos, e amplamente difundido pelo Comitê Consultivo em Meios de Vida Rural ${ }^{7}$. O primeiro órgão pertence à Universidade

\footnotetext{
${ }^{5}$ Por uma escolha de tradução preferiu-se manter os termos e a sigla no idioma original.

${ }^{6}$ No original em inglês a instituição é traduzida por Institute of Development Studies.

${ }^{7}$ No original em inglês o termo é traduzido para Sustainable Rural Livelihoods Advisory Committee.
} 
de Sussex e tem o objetivo de realizar pesquisas voltadas para os desafios da pobreza, injustiça global, entre outros. 0 segundo órgão pertence ao Departamento de Desenvolvimento Internacional (DFID) ${ }^{8}$ (DFID, 1999). 0 referido departamento é dos 24 ministérios do governo inglês, sediado em Londres. 0 órgão possui a função de liderar trabalhos contra a extrema pobreza, por meio de criação de empregos, oferecimento de serviços em educação, combate à violência, prevenção de desastres e ajuda humanitária.

Em 1991, Robert Chambers e Gordon Conway publicaram o artigo Sustainable rural livelihoods: practical concepts for the 21st century, considerado o trabalho inicial acerca do tema. 0 artigo tinha 0 objetivo de explorar e elaborar amplamente o conceito de sustainable livelihoods. As ideias eram baseadas em capacidade, equidade e sustentabilidade. Para os autores, livelihoods compreendem, em termos gerais, pessoas, seus recursos e seus significados de vida, e nesse contexto podem ser incluídos alimentação, renda, entre outros (CHAMBERS; CONWAY, 1991).

Para que a subsistência do pequeno produtor seja ambientalmente sustentável é necessário que este mantenha ou aumente os bens naturais tanto no ambiente local como para o global, principalmente relacionados àqueles a que sua própria subsistência está dependente. E como uma reação em cadeia também deve trazer benefícios para subsistências de outros tipos de produção, não diretamente relacionados a um único tipo de atividade (CHAMBERS; CONWAY, 1991).

De acordo com Yu (2004), o SLA trata-se de um enfoque baseado em uma perspectiva holística com o objetivo de debater a redução da pobreza e promover o desenvolvimento. O SLA apresenta cinco capitais (social, humano, financeiro, físico e natural) como ativos essenciais e necessários para uma vida sustentável. Esse modo de pesquisa social se diferencia dos demais em função do seu caráter pormenorizado nas análises e por desenvolver um trabalho participativo junto com a comunidade.

O SLA traz uma proposta analítica, amplamente conhecida no cenário internacional. 0 enfoque está voltado para o modo como a população pobre dos ambientes rurais desenvolve suas estratégias de enfrentamento às suas condições de vulnerabilidades (GRISA, 2009). A partir da visualização dos acessos aos cinco elementos é possível verificar suas condições de vulnerabilidade e a (des)igualdade nesses acessos.

O sustainable livelihoods approach (SLA) apresenta as formas requeridas para se obter a subsistência, e essas formas podem ser expressas por capacidades, direitos, acessos, entre outros. E para ser sustentável é preciso

${ }^{8} \mathrm{~A}$ sigla será mantida como no original em inglês, que corresponde a Department for International Development. corresponder aos padrões que permitem o crescimento, porém sem extinguir os recursos, no sentido de que as gerações futuras também possam usufruir destes. $E$ também contribuir com outros meios de vida em escala local e global (PERONDI; SCHNEIDER, 2012).

A pesquisa com o SLA se utiliza de um framework $^{9}$ (Figura 1) para analisar as diferentes formas de subsistência existente em um determinado ambiente, geralmente são aplicados para discutir a questões relacionadas ao espaço rural, no entanto também tem aplicabilidade para áreas urbanas (ELLIS, 2000). A subsistência é formada por um conjunto de diferentes forças e fatores que estão constantemente variando; ora, variam os aspectos econômicos, ora, os naturais, entre outros (DFID, 1999).

O framework (Figura 1) proporciona uma visualização de processos e atividades, o qual pode ser utilizado de diferentes formas pelos pesquisadores com vistas a redução da pobreza, sustentabilidade e estratégias de desenvolvimento. 0 framework é concebido a partir de um contexto de vulnerabilidade social e ambiental, da tendência à fome, da questão de gênero, das interações existentes entre a questão ambiental e a pobreza, dos problemas da pobreza urbana e dos modos de vida sustentável no campo (ELLIS, 2000).

A abordagem no SLA é aplicada comumente com indivíduos ou famílias em situação de pobreza. Normalmente, ela não é desenvolvida com grupos ou comunidades. Acredita-se que essa maneira de se fazer a pesquisa é fundamental para entender as opções de estratégias adotadas por cada indivíduo em busca da sobrevivência, considerando todos os aspectos da vulnerabilidade e as condições adversas de vida (ELLIS, 2000).

O framework (Figura 1) utilizado para as análises foi estabelecido para oferecer suporte na elaboração de micropolíticas, ou seja, políticas públicas voltadas para um grupo específico em espaços rurais, porém os resultados não se limitam a essa aplicação, as análises também servem para criação de macropolíticas, ou seja, políticas públicas voltadas para um público que compreenda o amplo número de pequenos produtores do País (ELLIS, 2000).

0 termo micropolíticas se refere às intervenções que afetam diretamente as opções de sobrevivência e as estratégias a nível local. Estas podem ser originadas do governo nas suas diversas esferas, ONGs e também pelas relações desenvolvidas entre os próprios produtores ou deles com outras organizações. As micropolíticas podem

${ }^{9} \mathrm{O}$ termo traduzido literalmente do inglês significa quadro, porém a palavra tem um sentido mais amplo que traz a ideia de base onde são estabelecidas estruturas, ou, para o caso deste trabalho, base de onde se podem retirar resultados a partir de determinadas análises. Nesse sentido, a palavra não terá uma tradução em português para que não se limite o sentido que se quer expressar. 
ser estabelecidas de diversas formas, por exemplo: taxas, subsídios, microcrédito ou outras formas de ações políticas que influenciem a sobrevivência da população local como a formação de associações, cooperativas ou outros grupos que lutem pelos objetivos do grupo, o que pode garantir a redução de tarifas, quebra de barreiras comerciais ou influenciar intervenções propostas (ELLIS, 2000).

Sob o ponto de vista da macropolítica os impactos podem ser mais significantes para os produtores de nível local e influenciar com maior intensidade suas estratégias de sobrevivência. Do mesmo modo como foram apresentadas intervenções para micropolítica, também podem ser originadas para a macro. Neste caso, questões como simplificação de procedimentos burocráticos, promoção de equidade através de decisões oficiais, remoção de barreiras de mercado do comércio em pequena escala são intervenções dependentes de operações do governo em um sentido mais amplo (ELLIS, 2000).

O framework (Figura 1) do SLA apresenta os fatores que afetam a subsistência dos produtores locais e as relações estabelecidas entre eles, além de também servir para o planejamento no desenvolvimento de novas atividades e avaliar a contribuição dos seus modos de vida para a sustentabilidade (DFID, 1999).

FIGURA 1 - Quadro do sustainable livelihoods approach

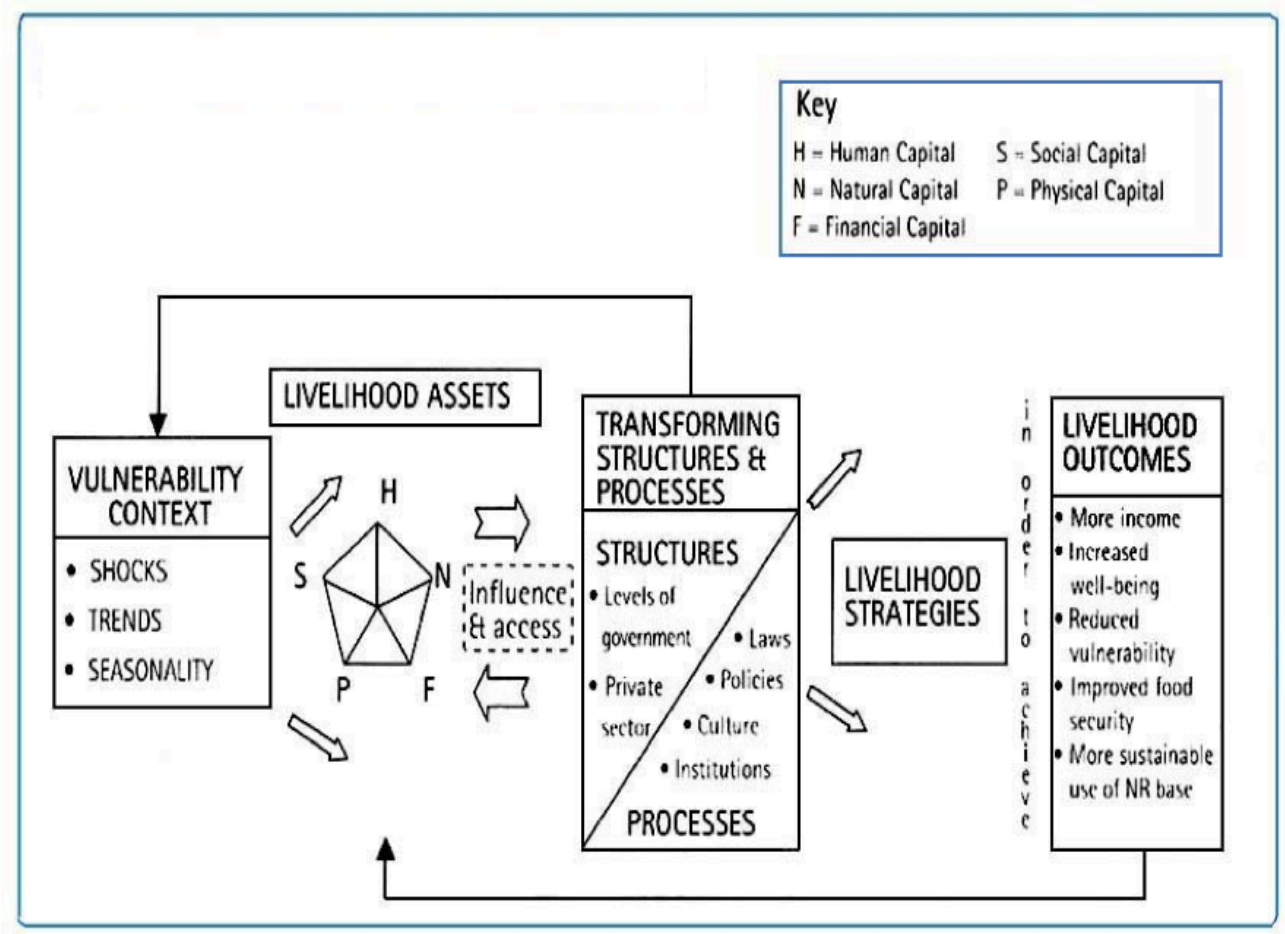

Fonte: DFID, 1999.

A formação do framework acima é composta por diversos elementos que somados podem contribuir para discussão em prol da redução da pobreza. Inicialmente, é elencado o Contexto de Vulnerabilidade (Vulnerability Context), onde são pontuadas questões do ambiente da população local e sua influência nos seus meios de vida. Em seguida, o contexto de vulnerabilidade é relacionado com os Ativos da Subsistência (Livelihood Assets), localizados no pentágono, e são divididos em capital humano, capital natural, capital financeiro, capital físico e capital social. Todos estes influenciam e sofrem Influências de Estruturas e Processos (Transforming structure and processes), normalmente regidas pelas esferas políticas e também por questões culturais, as quais também interagem com o contexto de vulnerabilidade. Diante deste primeiro momento, serão identificadas as Estratégias de Sobrevivência (Livelihoods Strategies), que surgem a partir dos resultados da interação dos processos anteriores, as quais têm o objetivo de encontrar Resultados das Condições de Vida (Livelihood Outcome), que podem ser o crescimento da renda, do bem-estar, a redução da vulnerabilidade etc. (DFID, 1999. Grifos nossos.).

Os Ativos da Subsistência são identificados por meio de um pentágono. Cada ângulo corresponde a um capital e o acesso a eles pode modificar o formato do polígono, caso os acessos sejam desiguais. Os capitais são divididos em humano, social, natural, físico e financeiro. 0 primeiro 
dessa lista representa as habilidades, conhecimento técnico e instrumentos (DFID, 1999).

$\mathrm{Na}$ continuidade da lista encontra-se o capital social, que, apesar dos debates acerca deste termo, no contexto do SLA significam as redes de contatos, relação patrãocliente, parceiros com interesses compartilhados, grupos formalizados como associações, cooperativas etc. E relações de confiança, reciprocidade e trocas, o que facilita a cooperação, a redução de custos e a segurança nas transações (DFID, 1999).

O capital natural vem em seguida, representando os recursos naturais necessários para a subsistência. $\mathrm{Na}$ sequência tem-se o capital físico, que compreende a infraestrutura básica e os bens que o produtor necessita para manter sua subsistência. O quinto capital é o financeiro, que são todos os recursos financeiros a que os produtores têm acesso com o objetivo de alcançar a subsistência, e aqui podem ser identificadas duas fontes principais: formas de poupança e regular acesso a rendimento como pensão ou salário (DFID, 1999).

Com o framework é possível identificar uma série de problemas e organizar um esboço para relacionar cada um deles. Também deve ser utilizado para visualizar com clareza as influências e os processos determinantes para subsistência dos produtores locais e enfatizar as múltiplas interações entre os vários fatores que afetam a subsistência dos produtores (DFID, 1999).

0 objetivo do framework do SLA é oferecer um suporte com diferentes perspectivas para engajar em um debate coerente acerca dos diversos fatores que afetam a subsistência, sua importância e o modo como eles interagem. Essa abordagem é de grande importância porque contribui na identificação dos pontos importantes que oferecem suporte à subsistência dos pequenos produtores (DFID, 1999).

0 framework foi criado para servir como uma ferramenta versátil no planejamento e na gestão. A ideia é também oferecer uma forma de pensar e debater a subsistência de pequenos produtores, como também entender a complexidade dos fatores que a influenciam. A contribuição esperada dessa ferramenta é o suporte para elaboração de meios para se discutir a eliminação da pobreza (DFID, 1999).

A utilização dessa metodologia requer algumas orientações para que se alcance 0 melhor que esse meio pode oferecer. Por exemplo, as pesquisas devem ser desenvolvidas de modo participativo. Durante a aplicação, o objetivo deve ser a neutralidade e o comprometimento com a luta em prol da eliminação das condições de pobreza. Dessa forma, pode ser estabelecido um importante diálogo com os parceiros para entender como os fatores políticos e econômicos contribuem com a perpetuação da pobreza no local. Esse uso deve ser associado com meios que possibilitem o reconhecimento de limitações para a subsistência, mesmo enfrentando os interesses das elites em encobrir ou distorcer os problemas para beneficiar a si mesmas. Dessa forma, é de suma importância habilidades prévias e rigor com a análise social (DFID, 1999).

Esta seção tem o objetivo de discutir as bases do "sustainable livelihoods approach" (SLA) de forma a encontrar pontos em comum com o debate desenvolvido na ecologia política. Dessa forma, esta pesquisa pretende provocar a discussão acerca do uso dessas abordagens como meios de estudo dos problemas existentes para subsistência dos reassentados de Petrolândia Nordeste do Brasil.

Implicações para subsistência dos pequenos produtores de coco dos assentamentos irrigados de Petrolândia-Pernambuco

O Município de Petrolândia, situado na porção pernambucana do Submédio São Francisco, sofreu inundação de parte do seu território para servir como reservatório da barragem de Itaparica, em função da instalação da Usina Hidrelétrica (UHE) Luiz Gonzaga, inaugurada em 1988 (Brasil, 2010).

A formação do reservatório repercutiu na transferência de aproximadamente 10.500 famílias para reassentamentos. Mais de 21 mil pessoas moravam nas áreas urbanas e mais de 19 mil habitavam nas áreas rurais. Os reassentamentos foram construídos com agrovilas e lotes dotados de sistemas de irrigação. Os assentamentos de Apolônio Sales e Icó-Mandantes são os mais antigos do Município de Petrolândia e diferentes em sua estrutura. 0 primeiro é o único em toda a região que não possui agrovila (SCOTT, 2009).

Após 27 anos da instalação dos reassentamentos na região de Itaparica, evidenciam-se os desafios para subsistência dos reassentados e seus descendentes (Domingues, 2009), em sua maioria produtores de coco. Um grupo de agricultores, desde o período da transferência forçada, foi instalado em terras sem aptidão para irrigação, onde as condições edáficas não são favoráveis para a instalação do sistema, visto que são terras com baixa permeabilidade, má drenagem, aumento natural de sais e elevada saturação por sódio trocável, caracterizando-se por solos naturalmente salinos. Dessa forma, tais produtores iniciaram sua nova vida em desvantagem econômica, alguns permanecendo assim até os dias atuais.

A maioria dos produtores enfrenta a questão da obsolescência da infraestrutura para irrigação instalada no final da década de 1980 e início da década de 1990, a qual não tem contribuído com o melhor uso dos 
recursos naturais. O sistema de irrigação apresenta diversos pontos de perda de água por rachaduras. Além da falta de manutenção em muitos trechos, inclusive nas estações de bombeamento, que acumula resíduo com facilidade, estes se transformam em barreiras naturais dentro da canalização empatando a distribuição pelo assentamento.

Outros produtores expandiram ilegalmente a sua área irrigada, em detrimento dos agricultores localizados no fim do sistema de distribuição, os quais não recebem a mesma quantidade de água daqueles que estão no início do sistema. Com a expansão das áreas irrigadas a água tem alcançado com muita ineficiência todo o conjunto. Essa situação é agravada diante do racionamento de água. Em períodos de estiagem a distribuição é limitada por algumas horas durante o dia. Diversos agricultores afirmam que o período de tempo do racionamento não é suficiente para o cultivo.

Os problemas com o acesso aos recursos naturais, neste caso, terra e água, resultam em um cenário de estagnação econômica para os pequenos produtores dos assentamentos irrigados de Petrolândia. Essas questões tomam uma dimensão amplificada quando são somadas a outros fatores como a desorganização institucional. Os produtores afirmam que não existe associação ou cooperativa de produtores reassentados que contribua com o escoamento do coco. Há mais de dez anos que eles não têm interesse nesse tipo de organização devido a problemas de corrupção entre os antigos líderes.

Os níveis de escolaridade e conhecimento técnico também são fundamentais para superar os problemas existentes. No entanto, grande parte dos produtores não frequentou a escola regularmente. Todos são dependentes de uma empresa que realize uma adequada assistência técnica e extensão rural, além de outra responsável pela manutenção dos equipamentos utilizados no cultivo. Mesmo assim, as empresas não têm funcionado em correspondência à demanda dos reassentados.

As dificuldades para acesso a crédito bancário são somadas aos problemas anteriormente citados. Os reassentados não disponibilizam de apoio governamental ou privado formal para consegui empréstimos nos bancos locais. Muitos são dependentes de uma verba de manutenção temporária (VMT), implantada após a transferência como medida provisória que porém permanece até hoje. Há estabelecimentos revendedores de insumos agrícolas e equipamentos que realizam um tipo de financiamento informal, e os produtores compram para pagar no período da colheita.

Frente a um cenário de conflito ambiental representado pela limitação ao acesso aos recursos naturais, crédito financeiro, extensão rural, serviços técnicos e manutenção, entre outros, produtores da região não apresentam forças suficiente para superar as barreiras do mercado, permanecendo às margens do sistema sem oportunidade de comercializar seus produtos diretamente. Os agricultores, quando não são excluídos do meio rural, tornam-se dependentes de grandes produtores ou de intermediários, os quais têm o controle sobre o acesso ao mercado e não compartilham dos ganhos igualmente com os reassentados.

Diante do exposto, é evidente que a realização de megaprojetos, como a construção de usinas hidrelétricas, além dos objetivos de crescimento econômico para uma região, também traz resultados negativos para os grupos excluídos da mesma região. Sob a luz da ecologia política e as ferramentas do sustainable livelihoods approach, pode-se identificar com clareza as desigualdades no acesso aos recursos naturais e como isso repercute na subsistência de pequenos produtores.

\section{Considerações finais}

Transformações ambientais provocam conflitos nas decisões políticas. Em diversos casos toda uma comunidade pode sofrer consequências graves de obras realizadas sem o planejamento ideal. Portanto, é necessário o reconhecimento do contexto histórico e das relações da sociedade com o ambiente antes de qualquer intervenção política sobre o ambiente.

A degradação ambiental, quando não abordada adequadamente, tem a tendência a aumentar, suplantando a economia de pequenos produtores, principalmente aqueles localizados em comunidades rurais. A falta de ação ou o enfraquecimento de grupos/ movimentos sociais retiram as oportunidades de reconstrução de vidas ou da reformulação do espaço habitado, perpetuando os pequenos produtores no conflito pelo acesso aos recursos naturais.

Os conflitos ambientais se apresentam normalmente pelo domínio do espaço por outros grupos, sem debater os novos usos da área com os antigos habitantes. Dessa forma, o ambiente é ocupado com práticas sem interação com o entorno, nem com a história local. O sustainable livelihoods approach, em conjunto com a ecologia política, sob a ótica dos conflitos ambientais, traz uma abordagem que oferece suporte para o debate sobre as questões das injustiças ambientais no campo brasileiro.

Os produtores dos reassentamentos de Petrolândia foram transferidos para novas áreas, porém muitos não dispõem de ativos mínimos para sobreviver. 0 acesso à água e à terra é frágil para alguns, enquanto para outros é inexistente, em função da falta de infraestrutura básica local. Os produtores não são organizados e possuem pouco engajamento político. A infraestrutura para captar 
a água e também para cultivar a terra não se apresenta da mesma forma para todos. Com esse cenário de conflito ambiental, a questão da subsistência nos reassentamentos torna-se mais complexa e a tendência é a expulsão dos pequenos produtores e o agravamento dos conflitos.

\section{Referências}

ACSELRAD, H. (2010) Ambientalização das lutas sociais - o caso do movimento por justiça ambiental. Estudos Avançados. São Paulo, vol. 24, n. 68.

ANDRADE, M. C. (2011) A terra e o homem do Nordeste: contribuição ao estudo da questão agrária no Nordeste. São Paulo: Cortez.

(1984) Poder político e produção do espaço. Recife: Fundação Joaquim Nabuco Massangana.

(1997) Josué de castro: o homem, o cientista e seu tempo. In: Estudos avançados. vol. 11 n. 29. São Paulo Jan / Apr. [on-line]. Disponível em: <http://www.scielo.br/scielo.php?pid=S010340141997000100009\&script=sci _arttext>. Acesso em: 1 out. 2015.

BRASIL. MINISTÉRIO DE MINAS E ENERGIA. CHESF. (2010) Responsabilidade social. [on-line]. Disponível em: <http://www.chesf.gov.br/portal/page/ /sustentabilidade_chesf/ sustentabilidade_ chesf_responsabilidade_social>. Acesso em: 1 nov. de 2012.

MINISTÉRIO DE INTEGRAÇÃO NACIONAL. CODEVASF. (2010) Sistema Itaparica. [on-line]. Disponível em: <http://www.codevasf.gov.br/ programas acoes /sistema-itaparica-1>. Acesso em: 2 nov. De 2012.

BRYANT, R. L., BAILEY, S. (2000) Third world political ecology. 4. ed. Abingdon, Nova lorque: Routledge.

CARVALHO, R. M. C. M. de O. (2009) Avaliação dos perímetros de irrigação na perspectiva da sustentabilidade da agricultura familiar no semiárido pernambucano. Tese de doutorado. Programa de pós-graduação em engenharia civil. Recife.

CHAMBERS, R.; CONWAY, G. R. (2015) Sustainable rural livelihoods: practical concepts for the $21^{\text {st }}$ century. IDS Discussion Paper, n. 296. 1991. [on-line]. Disponível em: <https://www.ids.ac.uk/ files/Dp296.pdf>. Acesso em: 10 out. 2014.

COY, M. (2013) Environmental justice? Sozialökologische konfliktkonstellationen in Amazonien. In: Umwelt und entwicklung im 21. Jahrhundert: Impulse und Analysen aus Lateinamerika. Nomos. Baden-Baden.

DFID. (1999) Sustainable livelihoods guidance sheets. London: Departament for International Development.

DIEGUES, A. C. S. (1989) Desenvolvimento sustentado, gerenciamento geoambiental e de recursos naturais. Cadernos FUNDAP, ano 9, 16:33-45.

DOMINGUES, R. de C. A. (2009) Aspectos institucionais da gestão dos recursos hídricos: o caso do Submédio São Francisco. Tese de doutorado. Programa de Pós-graduação em Geografia da UFRJ. Rio de Janeiro.

DOURADO, F. (2012) Aziz Ab'Saber, geógrafo e ambientalista. In: Instituto de Estudos Avançados da Universidade de São Paulo. São Paulo.17 mar. [on-line]. Disponível em: <http://www.iea.usp.br/ noticias/azizabsaber.html>. Acesso em: 20 de dez. 2015. 
ELLIS, F. (2000) Rural livelihoods and diversity in developing countries. Oxford (UK): Oxford University Press.

GRISA, C. (2009) Desenvolvimento local, políticas públicas e meios de vida: uma análise do programa de aquisição de alimentos (PAA). In: Sober. 47. Porto Alegre. Sociedade Brasileira de Economia, Administração e Sociologia Rural. [on-line]. Disponível em: <http://www.sober.org.br/ palestra/13/105.pdf>. Acesso em: 20 jul. 2015.

GUDYNAS, E. (2010) La ecología política de la crisis global y los limites del capitalismo benévolo. Íconos. Revista de ciencias sociales. Quito, n. 36, p. 53-67. Enero. [on-line]. Disponível em: <http:// www.flacso.org.ec/docs/i36gudynas.pdf>. Acesso em: 20 out. 2014.

GUIMARÃES, M. (2011) Além da geografia. Hilgard Sternberg dedicou a vida a entender as relações entre homem e natureza. In: Revista da FAPESP, ed. 182. Abr. [on-line]. Disponível em: <http:// revistapesquisa.fapesp.br /2011/04/03/al\%C3\%A9m-da-geografia/>. Acesso em: 19 ago. 2015.

GUNKEL, G., SOBRAL, M. C. (2007) Reservoirs and River Basins Management: Exchange of Experience from Brazil, Portugal and German. Berlin, Germany: Universitätsverlag der TU Berlin.

HARVEY, D. (2005) El "nuevo" imperialismo: acumulación por desposesion. Trad. Ruth Felder. Socialist register. 2004 (enero 2005). Buenos Aires, CLACSO. [on-line]. Disponível em: <http:// biblioteca.clacso. edu.ar/clacso/se/20130702120830/harvey.pdf>. Acesso em: 30 jan. 2015.

IBGE. (2006) Cidades. Censo agropecuário. [on-line]. Disponível em: <http://www.ibge.gov.br/ cidadesat/topwindow.htm?1>. Acesso em: 23 mar. 2013.

Malha Municipal Digital. [on-line] (2010) Disponível em:

<ftp://geoftp.ibge.gov.br/ mapas/malhas_digitais/>. Acesso em: 20 ago. 2010.

KRINGS, T. (2013) Politische Ökologie. In: Geographie: physische geographie und humangeographie. 2. ed. Heidelberg: Spektrum Akademischer Verlag.

MCCUSKER, B., D. WEINER. (2003) GIS Representations of Nature, Political Ecology, and the Study of Land Use and Land Cover Change in South Africa. In: ZIMMERER, Karl S.; BASSETT, Thomas J. (Orgs.). Political ecology: an integrative approach to geography and environment-development studies. New York, London: The Guilford press.

MAIA, D. S. (2009) O pensamento de Manoel Correia de Andrade e a sua obra A Terra e o Homem no Nordeste. In: RIBEIRO, Wagner Costa; SOARES, Paulo Roberto Rodrigues (Orgs.). Cidadania e reforma agrária no Brasil: a herança de Manuel Correia de Andrade. Scripta Nova: Revista eletrónica de geografía y ciencias sociales. Barcelona. v. XIII, n. 288, abr. Disponível em: <http://www.ub.edu/ geocrit/sn/sn-288.htm>. Acesso em: 20 dez. 2015.

PEREIRA, M. A.; SOUZA, M.; SCHNEIDER, S. (2010) Meios de vida e livelihoods: aproximações e diferenças conceituais. Revista Ideias. Rio de Janeiro. v. 4, n. 1, p. 203-224, jun-jul. Disponível em: <http://www.ufrgs.br/pgdr/arquivos/775.pdf>. Acesso em: 15 jul. 2015.

PERNAMBUCO. CONDEPE/FIDEM. (2008) Perfil municipal de Petrolândia. Recife.

PERONDI, M. A.; SCHNEIDER, S. (2012) Bases teóricas da abordagem de diversificação dos meios de vida. In: Redes - Revista de Desenvolvimento Regional. Santa Cruz do Sul, v. 17, n. 2. maio/ago. [on-line]. Disponível em: <http://online.unisc.br/seer/index.php/redes/ article/view/2032/2175>. Acesso em: 19 jul. 2015.

ROBBINS, P. (2005) Political Ecology: a critical introduction. 4. ed. Série: Critical Introductions to Geography. Oxford: Blackwell publishing.

SANDERS, R. (2011) Amazon expert Hilgard O’Reilly Sternberg dies at 93. In: Berkeley News. Campus News. [on-line]. Disponível em: <http://news.berkeley.edu /2011/03/04/amazon-experthilgard-o\%E2\%80\%99reilly-sternberg-dies-at-93/>. Acesso em: 30 ago. 2015. 
SCOTT, P. (2009) Negociações e resistências persistentes: agricultores e a barragem de Itaparica num contexto de descaso planejado. Recife: Editora Universitária da UFPE.

SILVA, E. R. (1998) O curso da água na história: simbologia, moralidade e a gestão de recursos hídricos. Rio de Janeiro: Fundação Oswaldo Cruz/ Escola Nacional de Saúde Pública. 166 p. Tese de doutorado em saúde pública, PPG em Saúde Pública, Escola Nacional de Saúde Pública. Rio de Janeiro.

SVAMPA, M. (2013) Consenso de commodities y linguajes de valoración em América Latina. Nueva Sociedad. Buenos Aires, n. 244. mar-abr. Disponível em: <http://nuso.org/ media /articles/downloads/3926_1.pdf>http://www.scielo.br/scielo.php?script= sci_ arttext\&pid=S0104-71832006000100008. Acesso em: 20 out. 2014.

YU, C. M. (2004) Sequestro florestal de carbono no Brasil: dimensões políticas, socioeconômicas e ecológicas. Curitiba. Tese (Doutorado em Meio Ambiente e Desenvolvimento). Departamento de Ciências Agrárias. Universidade Federal do Paraná. Disponível em: <www.iieb.org.br/index.php/ download_file/956/1149/>. Acesso em: 1 maio 2015.

ZHOURI, A. (2006) 0 ativismo transnacional pela Amazônia: entre a ecologia política e o ambientalismo de resultados. Horizontes Antropológicos. Porto Alegre, ano 12, n. 25, p. 139-169, jan-jun. [on-line]. Disponível em: <http://www.scielo.br/scielo.php?script= sci_ arttext\&pid=S0104-71832006000100008>. Acesso em: 20 abr. 2015.

ZIMMERER, K. S.; BASSETT, T. J. (2003) Approaching political ecology: society, nature and scale in human-environment studies. In: ZIMMERER, Karl S.; BASSETT, Thomas J. (Orgs.). Political ecology: an integrative approach to geography and environment-development studies. New York, London: The Guilford Press. 